the truly wonderful $\mathrm{X}$ ray work of Dr. A. C. Jordan. As these changes are present there can be little doubt that some results must accrue from them, and those of us who are in general practice are quite familiar with the two types of cases described: the chronic invalid with general proptosis and continual abdominal discomfort, indigestion, and constipation; and the other type, who only suffers from a "difficulty with his bowels" or "his liver," as he prefers to call it, and who eventually develops cancer. These two types being familiar to us, are we to accept the conclusions which the author draws? That is to say, are we to prognose that the first type will develop cancer or rheumatoid arthritis in some distant organ or joint, and that the second type will get cancer locally? Or, in other words, that the person who has these changes well marked is doomed to disease sooner or later. It seems to me that this is very nearly a proved case, and that we are bound to accept the theory as a basis (for our conception) at any rate for the present, or until it can be proved by further research to be untrue. This, then, is a very serious position; certain well-known diseases of mortal importance to the sufferers, a definite anatomical cause accepted for the diseases, but no theory for the abdominal changes which are proved to exist. If these anatomical conditions of the contents of abdomen are not congenital they must be produced by some error or errors of management in childhood.

I revert now to the good lady who was so indignant with me in the out-patient department of the hospital. She insisted that the proper diet for a child was "a bit of what we have ourselves." I, in my superior wisdom, told her that the only diet for a child of 8. months was milk, which was to be continued until the child was 9 months old, and that after that time farinaceous food was to be gradually added to the milk, which was not to be decreased in quantity. Hence her contempt for me! Now in watching children grow and develop during the many years I have been in practice I have been struck with the little importance that seems to be placed on diet, so long as it is "digestible and nourishing"; these are the only two epithets ever applied to food, and what is meant by "digestible" is that there must be no overt act of indigestion, such as pain or wind. The more the child can eat of this kind of diet and the fatter it grows the more pleasure is given to the parents. The child may, and often does, require a "dose," but that is "only what all children want," and nothing is ever thought of it. An ordinary child starts the day with a breakfast consisting of bread and butter, an egg or some fish, and half pint of milk; in the middle of the morning it is given half pint of milk and some food of some sort-biscuits, rusk or bread; at from 1 to 1.30 it has a full meal of meat or fish, vegetables, and a pudding, generally a milky one; at 4.30 it has a good tea meal with jam to stimulate its jaded appetite, and half pint of milk; and at bed time it has another small meal. Altogether the child takes five meals daily, and no mother is satisfied unless it drinks at least two pints of milk in addition, and very often sweets are given as extras-I mean sweets of which sugar is the principal ingredient. All this food is of the digestible sorti.e., all elements of it which are considered to be indigestible are carefully eliminated either by the nurse or mother. Now it must be confessed that the great majority of children pass through this period of their lives successfully, and no matter what they eat, or how much, they seem to keep well and remain free from disease. But certain of them fall by the way, and of these a good many are sufferers from dyspeptic troubles, loss of appetite, pain in the stomach, and flatulence. In many of these cases it is very easy to follow cause and effect, and if the diet, and especially the number of meals, is reduced improvement rapidly follows. A typical case is the following :-

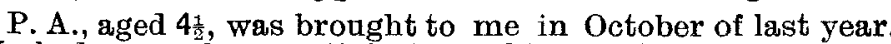
He had never been satisfactory; his appetite was bad, he suffered from abdominal pains, he was "anæmic," he slept badly, and was very easily tired. His bowels acted daily, but his motions were small, and sometimes there was a little "mucus" in them. He had been to many doctors, who could find nothing physically wrong, had ordered him tonics, and told his mother to feed him up. He was a bright intelligent little fellow, very pale but not anæmic, and could find no physical change except a distended tumid abdomen. I told his mother to stop two of his meals daily, and to substitute fruit and vegetables for most of his farinaceous food, and only to give milk as a condiment. The improvement was miraculous, and he lost all his symptoms for two months, when he suffered a slight relapse owing to constipation returning in the very cold spell of weather which we experienced in December.

Now I believe that this lad is in the early stage of abdominal change, and that he will be easily cured by the recognition of his condition. He was suffering from overfeeding and unsuitable feeding, which I believe to be the case with the majority of presentday children, and that, furthermore, it is the cause of the changes that are described.

In order to avoid the results it will be necessary to make considerable changes in the method of feeding children for the future. First of all, there must be a diminution in the number of meals, the most that may be allowed being three in the day. This allows time for one meal to be digested before another is poured into the stomach. The latter organ is thus not overfilled, and does not tend to become distended, the food is properly digested and passed on to the intestine in a fit condition for the further processes of digestion, and no overloading will take place. Then there must be great alterations of the food itself. As I have said before, all the mother asks of food at the present time is that it shall have three qualitiesdigestibility, nutritiousness, and quantity. No thought is taken as to the time that this diet will take in its passage through the digestive canal, and constipation is not looked upon as indigestion. It is as a rule easily corrected by a dose of medicine, and therefore of little importance. Now what is the most important acquisite of food? I unhesitatingly say its power of rapidly passing through the intestinal canal. If food passes in the proper time through these organs well and good. No matter what its quality or what its quantity no harm accrues, but if from any reason it lags by the way trouble begins. This is true stasis. Now this happens in our modern dietary, because all the laxative properties of food are carefully kept a way from the child, as they are contained in that part of it which is usually called indigestible. The peels of potatoes, of apples, and other fruits, the stalks of cabbage and caulifiowers, the husks of all grain, are the necessary ingredients for stimulating the bowel to act, and they are carefully withheld from children, as they contain no nourishment and are "indigestible." Few children are allowed to eat raw fruit for the same reason, and consequently we see the results-stasis and its after-effects. Too much milk, too much straining after " nourishment," too many patent " pap" foods, are the reigning desiderata at the present time, whereas nature is quite able to pick out from even a scanty diet sufficient nourishment for the development of most children, if it is allowed to go its own way, undisturbed by tonics, digestives, and "doses."-I am, Sir, yours faithfully,

Buckingham-gate, S.W., Jan. 16th, $1921 . \quad$ H. A. DES VquX.

\section{ORAL SEPSIS,}

WITH SPECIAL REFERENCE TO CHRONIC DENTAL APICAL INFECTION

To the Editor of THE LANCET.

SIR,-The interesting paper by Dr. W. Bertram Watson on this subject in your issue of Jan. 1st drew attention to a special feature of oral sepsis which is, in my experience, too often overlooked by dental surgeons and medical practitioners. I refer to a chronic dental infection, often round the apex of the root where the gums and teeth are, as far as can be judged from careful macroscopical examination, perfectly healthy, and where no tenderness or pain are experienced by the patient. Too often in these cases the healthy appearance of the teeth has caused them, or rather the bony cavities containing them, to be disregarded as possible foci of serious infection without further examination. It cannot be too strongly urged that in all cases where the symptoms may be due to a 
chronic septic infection of unknown origin the jaw can only be excluded as a causal factor after a careful $X$ ray examination has been made, and this should be done however healthy the appearance of the gums and teeth. It is remarkable how frequently cases of fibrositis, arthritis, and similar chronic conditions are met with in which, though the gums and teeth appear perfectly healthy, an $X$ ray examination discloses definite septic foci round the apices of the teeth.

At the recent pathological meeting of the Medical Society of London on Jan. 10th, Sir William Hale-White and myself referred to a case of malignant endocarditis where the source of the infection was directly traceable to a septic focus round the apex of the left lower central incisor tooth. In this case an $X$ ray examination by Mr. C. A. Clark revealed a small abscess, though to ocular examination the gums and teeth appeared perfectly healthy. I am strongly of opinion that oral sepsis is one of the most important causes of gastric and duodenal ulcer and that the septic absorption of pathogenic streptococci often takes place through the blood stream, the gums and teeth appearing externally healthy. There is considerable experimental evidence by Rosenow and others to confirm this view. Certainly, however healthy may be the appearance of the gums, an $X$ ray examination of the teeth should be made in every suspected case of peptic ulcer.

$$
\text { I am, Sir, yours faithfully, }
$$

W. H. WILLCOX.

Welbeck-street, Cavendish-square, W., Jan. 24th, 1921.

\section{MALARIA IN THE EAST AFRICAN CAMPAIGN.} To the Editor of THE LANCET.

SIR, -Little has been published respecting the medical aspects of the campaign in East Africa, and the papers of Majors J. P. Johnson and K. Gilchrist ${ }^{1}$ and of Majors Johnson and Gilchrist and E. Hay-Michel ${ }^{2}$ are a welcome contribution of the greatest interest and importance. After clinical and laboratory experience in various hospitals in G.E.A. during 1916-1919 I should like to endorse many of their findings. In 1000 blood smears, most of them thick drops, I had 40 per cent. positive, of which 71 per cent., B. tertian; 26 per cent., subtertian; 3 per cent., mixed B.T. and S.T.; under 1 per cent., quartan. They made no mention of quartan infections; at Morogero I saw two cases in natives and only one case in a white man, so that possibly none were invalided to South Africa. Their figures naturally show a higher proportion of mixed infections, as these were more refractory to treatment and were therefore more liable to be invalided to South Africa. Higher dosage of quinine became the rule in the last one and a half years of the campaign, though medical officers new to the country often began with small "tonic" doses. In some hospitals a dosage of $60 \mathrm{gr}$. per diem was not uncommon. In my own cases I obtained better results with three-hourly doses of $10 \mathrm{gr}$. given as early in an attack as possible to a maximum of 30-40 gr. When an attack had been missed we endeavoured to produce mild tinnitus before the next rigor was due. In fact, the presence of tinnitus aurium was taken as a rough test of the absorption of quinine into the system. ${ }^{3}$ In the subtertian type of infection with continued fever it is important that repeated small doses should be given throughout the night as well as the day to a maximum of $45 \mathrm{gr}$. in 24 hours. I often thought that the omission of quinine between 6 P.M. and 8 A.M. accounted for the fact that medical officers could not control these cases with oral quinine. Majors Johnson and Gilchrist rightly lay great stress on the presence of parasitological as well as of clinical relapses. Unfortunately, "bed-space" was the deciding factor in hospitals in G.F.A., and it was late in the campaign before convalescent camps (Dodoma and Nakuru) had the benefit of a laboratory. The paper is a striking demonstration of the fact that only by repeated blood examination can one judge of the effects of our treatment, a matter which has been too often disregarded in weighing the merits of different drugs and modes of administration. The relapse of 14 per cent. of previous "negatives" is not higher than one would expect. The promotion of the general powers of resist. ance of the body is duly appreciated by Majors Johnson and Gilehrist. During the years 1917-1918 how futile were our drugs against the effects of climate and the debility of our patients, and how striking the difference made by evacuation to Nairobi, Kijabe, and Nakuru (4000 feet).

As regards treatment with "606" I can testify to the beneficial effect in malarial cachexia and in the convalescent stage of blackwater fever. Captain D. S. Harvey, of the 15th Stationary Hospital, and later myself, used it (intramuscularly) in several cases, and Dr. R. W. Burkitt, of Nairobi, B.E.A., has elsewhere published his good results in civil cases. The action of arsenic as a stimulant to the hæmopoietic system is to cause a better type of red cell to be passed into currency, the spleen has thus less destructive work to do, gets rid of its débris and hence becomes smaller. I believe that the shrinking of the spleen is as much due to this as to any diminished activity of malarial parasites. I cannot help thinking. that the effects on the liver which they ascribe to arsenic are chiefly due to the catharsis and light diet. In our V.D. section it was not unusual for an attack of malaria to occur within 48 hours after injection of " 606 " " and in the few cases of malaria in which I tried " 606 " alone had eventually to be given quinine. I am, therefore, most sceptical about the parasiticidal action of arsenic in malaria. The great lesson of their paper is that chronic malaria in debilitated subjects can be overcome only by adequate quininisation, combined with general tonic measures and that constant blood examination is necessary to control the treatment.

I am, Sir, yours faithiully,

W. S. DAWSON, M.B., M.R.C.P.,

Hanwell, Jan. 16th, 1920 Late 15th Stationary Hospital, G.E.A.

\section{INSURANCE MEDICAL RECORDS.}

To the Editor of THE LANCE'.

SIR,-At this juncture the leading article in your issue of Jan. 8th serves a very useful purpose. Just such a reasoned and sane pronouncement is much needed, for the numerous meetings held to discuss the record cards have been marked by much unwisdom in speech and resolution. Had these proceedings taken place in camera it would have been deplorable enough, but, unfortunately, in most instances the presence of pressmen has been courted, and their reports, as presented in the various papers, partake either of the nature of political propaganda or light comedy, and do little to uphold the dignity or intelligence of the medical profession.

At the very outset of the insurance agitation years ago $\mathrm{Mr}$. Lloyd George was reported to have said: "Remember, National Insurance is not merely a doctor's endowment society," and we should do well to keep this pronouncement in mind. We may take what is called "panel practice" to be the germ, or foundation, of what it is hoped will one day grow into an efficient State Medical Service. Even now panel doctors are State servants holding a Government con tract with definite conditions, of which record keeping is one. As State servants we have no concern with political or other like considerations. Our duty is to loyally carry out the terms of the contract we have accepted. Undoubtedly the record cards present features open to discussion, but they are sound in principle, a step in the right direction, and a great advance on the previous card system. If we approach the health authorities in a reasonable spirit, in time improvements will doubtless be made, but there is little in the present agitation to encourage the Department to give us a patient hearing. Is it reasonable to claim that the medical any more than any other profession is entirely faultless? There are doctors who do, and doctors who do not, take their panel practice seriously and probably for all of us, and certainly for the latter it is a good thing that we should have, in the record cards, to give an account of our stewardship.

I am, Sir, yours faithfully

Havant, Jan. 22nd, 1921.

ARTHUR J. GEDGE. 